\title{
Aplikasi Optimalisasi Pengiriman Barang Menggunakan Metode Tabu Search Berbasis Web
}

\author{
Putu Irvan Arya Purwadana, Dwi Putra Githa, Desy Purnami Singgih \\ Program Studi Teknologi Informasi, Fakultas Teknik, Universitas Udayana \\ Bukit Jimbaran, Bali, Indonesia, telp (0361) 701806 \\ e-mail: purwadanaarya@gmail.com, dwiputragitha@gmail.com, desysinggihputri@gmail.com
}

\begin{abstract}
Abstrak
Tujuan pengiriman barang adalah menyampaikan barang dalam kondisi yang baik dan cepat. Pengiriman barang berjalan efisien apabila memperhatikan faktor pengiriman barang yaitu, wilayah dan muatan. Masalah pengiriman barang yang biasanya terjadi yaitu pengiriman dilakukan secara acak dan barang yang dikirim tidak sesuai kapasitas kendaraan. Masalah tersebut menjadi latar belakang pembuatan aplikasi optimalisasi pengiriman barang. Aplikasi optimalisasi pengiriman barang bertujuan untuk mencari rute pengiriman barang yang optimal tidak hanya berdasarkan jarak tapi juga muatan. Metode Tabu Search digunakan pada aplikasi optimalisasi pengiriman barang untuk mencari rute pengiriman terbaik dari beberapa alternatif rute yang terbentuk. Aplikasi optimalisasi pengiriman barang memanfaatkan Google Maps untuk mendapatkan jarak pengiriman dan visualisasi rute pengiriman. Hasil dari aplikasi optimalisasi pengiriman barang yaitu menentukan barang yang dikirim oleh kendaraan, rute pengiriman barang yang optimal dan visualisasi rute dalam bentuk maps.
\end{abstract}

Kata Kunci: Pengiriman Barang, CVRP, Metode Tabu Search.

\begin{abstract}
Purpose of shipping is deliver items to the intended place in good condition and quickly. Shipping runs efficiently when keep attention to the factors of shipping, namely the area and capacity. Shipping problems that usually happen are shipments carried out randomly and goods sent doesn't fit to the capacity of vehicle. Its become the references of making this application. This application purpose to find optimal shipping route not only by distance but also capacity. Tabu search method used in this application to find the best shipping route. This application utilizes Google Maps to get shipping distances and route visualization. The results of this application are which items will be sent by each vehicle, shipping route and visualization of the route in the maps.
\end{abstract}

Keywords: Shipping Item, CVRP, Tabu Search Method.

\section{Pendahuluan}

Pengiriman barang bertujuan untuk menyampaikan barang ke tempat tujuan dengan cepat dan dalam kondisi yang masih baik. Pengiriman barang yang efektif dan efisien dapat mengurangi waktu dan biaya yang dihabiskan untuk melakukan pengiriman barang. Pengiriman barang dapat berjalan efisen apabila memperhatikan faktor-faktor penting dalam pengiriman barang yaitu faktor wilayah dan muatan. Faktor wilayah dan muatan diperlukan agar pengiriman barang menjangkau wilayah secara menyeluruh serta daya angkut kendaraan mencapai titik optimal.

Masalah akan timbul apabila tidak terpenuhinya faktor-faktor pengiriman barang yaitu wilayah dan muatan sehinga berdampak pada efisiensi pengiriman barang. Masalah wilayah biasanya terjadi karena pengiriman barang dilakukan secara acak tanpa melalui rute optimal. Masalah muatan barang yang bisa berlebih atau kurang dari kapasitas kendaraan menjadi masalah yang sering dialami pada proses pengiriman barang.

Model permasalahan pencarian rute dengan memperhatikan kapasitas pada pengiriman barang ini termasuk model permasalahan CVRP (Capacitated Vehicle Routing Problem). CVRP 
merupakan masalah praktikal seperti distrubusi dan pengiriman barang dengan tujuan menentukan rute dengan cost yang minimum [1]. Penelitian yang ditulis oleh Marchalia Sari dengan judul "Penyelesaian Capacitated Vehicle Routing Problem menggunakan Saving Matriks, Sequential Insertion dan Nearest Neighbour di Victoria RO" menggunakan input daftar jarak pelanggan, daftar permintaan dan kapasitas kendaraan untuk permasalahan CVRP [2]. CVRP atau masalah pengiriman barang dapat diatasi dengan menggunakan metode metaheuristik yang menghasilkan solusi mendekati optimum dengan waktu yang singkat [3]. Contoh metode metaheuristik adalah metode tabu search. Metode tabu search digunakan dalam penelitian Sulistino dan Noor Saif Muhammad yang berjudul "Rancang Bangun Vehicle Routing Problem Menggunakan Algoritma Tabu Search" untuk mencari rute pengiriman barang dengan jarak terpendek dan optimal [4]. Penelitian lain yang ditulis oleh Sami Faiz dengan judul "A DSS Based on GIS and Tabu Search for Solving the CVRP: The Tunisian Case" menyatakan bahwa metode tabu search mampu mencari solusi diluar solusi optimal lokal [5].

Mengacu pada penelitian sebeumnya, pengembangan yang dilakukan pada penelitian aplikasi optimalisasi pengiriman barang adalah adanya proses clustering. Proses clustering dilakukan untuk memilih barang mana saja yang dikirim untuk masing-masing kendaraan dengan memperhatikan kapasitas maksimum kendaraan. pembentukan rute tidak hanya memperhatikan jarak namun juga muatan. Kelebihan lain dari aplikasi optimalisasi pengiriman barang adalah terdapat visuliasi rute pengiriman barang dalam bentuk maps sehingga memudahkan pengirim menuju lokasi pengiriman.

\section{Metodologi Penelitian}

Tahapan penelitian dari aplikasi optimalisasi pengiriman barang yaitu melakukan observasi masalah yang biasanya terjadi pada pengiriman barang yaitu masalah wilayah dan muatan. Analisa kebutuhan dilakukan setelah mendapatkan masalah pengiriman sehingga didapatkan bahwa kebutuhan aplikasi yaitu pencarian rute dan visualisasi pada maps. Pencarian teori penunjang dan metode untuk menyelesaikan masalah sehingga didapatkan metode tabu search. Masalah pengiriman barang tersebut diuraikan dan studi literatur untuk menganalisa kebutuhan dan mencari teori penunjang pengembangan aplikasi. Tahap pemodelan sistem menguraikan metode, proses perhitungan dan output yang dihasilkan aplikasi. Tahap perancangan dan desain meliputi pembuatan database dan GUI. Tahap pengembangan sistem mulai melakukan koding. Tahap uji coba melakukan pengujian fungsi yang ada pada sistem bekerja dengan baik dan menghasilkan rute pengiriman barang yang optimal. Tahap terakhir adalah pembuatan laporan apabila tahap uji coba berhasil dilakukan.

\subsection{Gambaran Umum}

Gambaran umum dari Aplikasi Optimalisasi Pengiriman Barang menggunakan Metode Tabu Search Berbasis Web dapat dilihat pada Gambar 2.

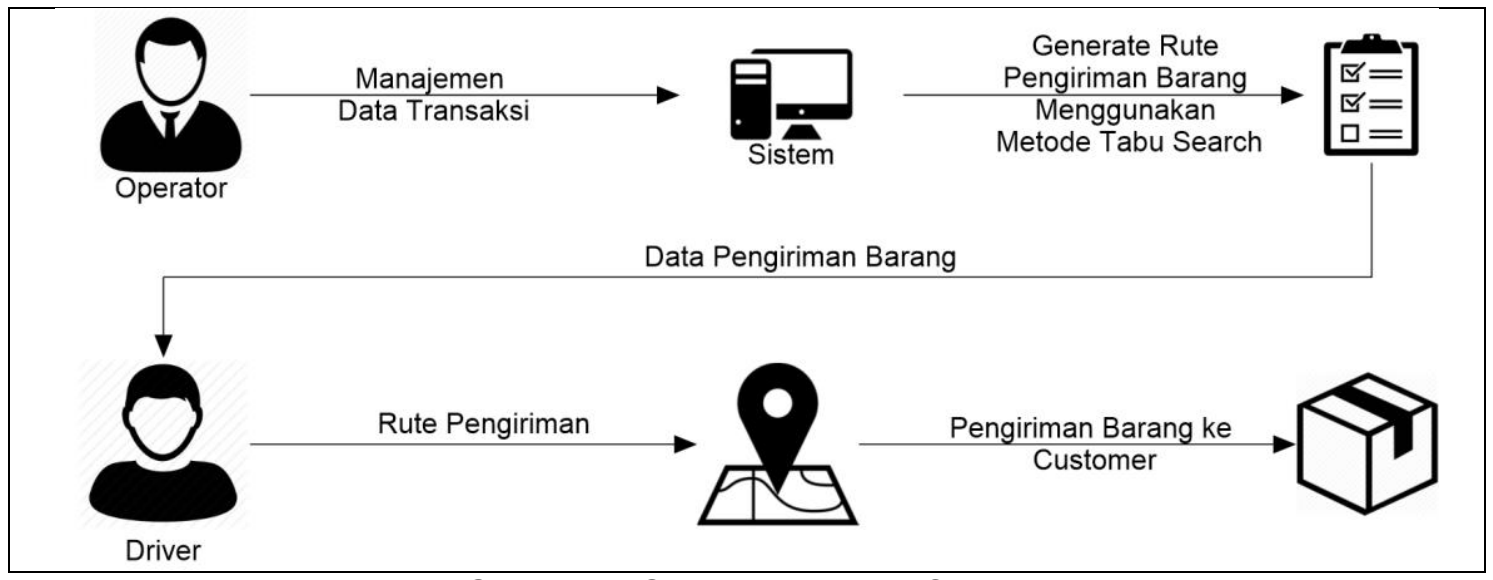

Gambar 2. Gambaran Umum Sistem

Gambar 2 menampilkan gambaran umum aplikasi optimalisasi pengiriman barang. Entitas yang terlibat pada aplikasi optimalisasi pengiriman barang yaitu operator, driver dan admin. Entitas admin dapat melakukan pengolahan data user. Entitas operator dapat melakukan 
pengolahan data transaksi kemudian generate rute pengiriman barang. Proses generate rute menggunakan metode tabu search, dimana semua data transaksi terlebih dahulu dikelompokkan sesuai dengan kapasitas kendaraan kemudian dicari rute pengirimannya. Hasil rute pengiriman brang dapat dilihat oleh driver kemudian driver dapat melakukan pengiriman barang. Status pengiriman barang dapat diubah oleh driver apabila barang telah dikirim.

\section{Kajian Pustaka}

Teori dan teknonologi penunjang pengembangan aplikasi optimalisasi pengiriman barang menggunakan Metode Tabu Search berbasis web akan dijelaskan sebagai berikut.

\subsection{Teori Graph}

Graph menggambarkan garis yang menyatukan dua buah titik. Graph dapat dibedakan berdasarkan arahnya yaitu directed graph dan undirected graph. Directed graph merupakan graph yang mempunyai arah sedangkan undirected graph merupakan graph yang tidak mempunyai arah atau graph yang melakukan pergerakan dari satu node ke node yang lain dan sebaliknya. Contoh graph adalah jalan raya dan sungai [6].

\subsection{Capacitated Vehicle Routing Problem (CVRP)}

Capacitated Vehicle Routing Problem (CVRP) merupakan pengembangan dari VRP dengan menambahkan kendala kapasitas kendaraan [7]. Tujuan CVRP mencari rute dengan cost yang meminimalkan dalam pengiriman barang. Kendala pada CVRP adalah total permintaan agen dalam satu rute tidak melenihi kapasitas kendaraan, agen hanya dikunjungi satu kali dan rute berawal dan berakhir pada depot [8].

\subsection{Sistem Informasi Geografis}

Sistem informasi geografis merupakan sistem untuk melakukan pengolahan data spasial. Pengolahan data spasial yang dilakukan pada sistem informasi geografis yaitu memasukkan, menyimpan, mengelola, menganalisa dan mengaktifkan kembali data keruangan atau spasial yang berkaitan dengan pemetaan [9]. Sistem Informasi Geografis. Fungsi dari sistem informasi geografis adalah mengumpulkan, menyimpan dan analisis dan fenomena geografis. Aplikasi sistem informasi geografis dapat menentukan lokasi, tren, pola dan pemodelan berdasarkan suatu wilayah geografis. Sistem informasi geografis memberikan informasi dalam bentuk peta. [10].

\subsection{Google Maps dan Google Maps API}

Tahun 2005, Google mengeluarkan layanan peta online yang dengan nama google maps. Google maps. Google maps menggunakan interaksi client-server untuk mengunduh informasi dari peta. Pengembangan sistem informasi geografis dikembangkan dengan google maps untuk melakukan pemetaan [11]. Google maps API diperkenalkan oleh Google bulan Februari tahun 2005 untuk dapat menggunakan peta digital pada berbagai macam aplikasi. Google Maps API memudahkan kerja maps pada web dengan menggeser dan menggerakkannya [12]. Google maps API berfungsi untuk mengintegrasikan google maps ke situs web pengguna sehingga dapat menampilkan peta digital. Penggunaan google maps API harus menggunakan maps API java script agar google maps dapat muncul [13].

\subsection{Metode Tabu Search}

Metode tabu search tergolong metode heuristik dimana pencarian solusi menggunakan short term memory agar tidak terjebak pada nilai optimum lokal. Metode ini mencari solusi terbaik pada setiap iterasi dan memasukkannya pada tabu list. Solusi yang sudah ada pada tabu list tidak akan dievaluasi lagi. Tabu list berisi solusi terbaik dari setiap iterasi kemudian diseleksi hingga mendapatkan solusi yang paling optimal [14]. Langkah perhitungan dalam algoritma tabu search dapat dijelaskan sebagai berikut.

1. Langkah 1 : Pilih Solusi awal $i$ dalam himpunan $S$. Tetapkan $i^{*}=i$ dan $\mathrm{k}=0$ dimana $i^{*}$ adalah solusi terbaik dan $k$ adalah banyaknya perulangan yang terjadi saat dilakukannya pencarian solusi terbaik $i^{*}$. 
2. Langkah 2 : Tetapkan $k=k+1$ dan hasilkan himpunan bagian $V^{*}$ dari solusi dalam solusi himpunan $N(i, k)$ sehingga tabu conditions tidak memenuhi dan aspirations conditions terpenuhi.

3. $\quad$ Langkah 3 : Pilih solusi terbaik $j$ dalam himpunan bagian $V^{*}$ tetapkan $i=j$.

4. $\quad$ Langkah 4 : Jika $f(i) \leq f\left(i^{*}\right)$ maka tetapkan $i^{*}=i$.

5. Langkah 5 : Update tabu dan aspirations conditions.

6. Langkah 6 : Jika kondisi berhenti (stopping conditions) terpenuhi, maka pencarian berhenti. Jika tidak, lakukan langkah 2.

\section{Hasil dan Pembahasan}

Hasil dan pembahasan akan menjelaskan tentang perancangan sistem dan implementasi sistem.

\subsection{Perancangan Sistem}

Diagram konteks dan struktur database yang digunakan dalam perancangan aplikasi optimasi pengiriman barang.

a. Diagram Konteks

Diagram konteks menjelaskan aliran data terhadap entitas-entitas yang ada pada aplikasi optimasi pengiriman barang yang dapat dilihat pada Gambar 3.

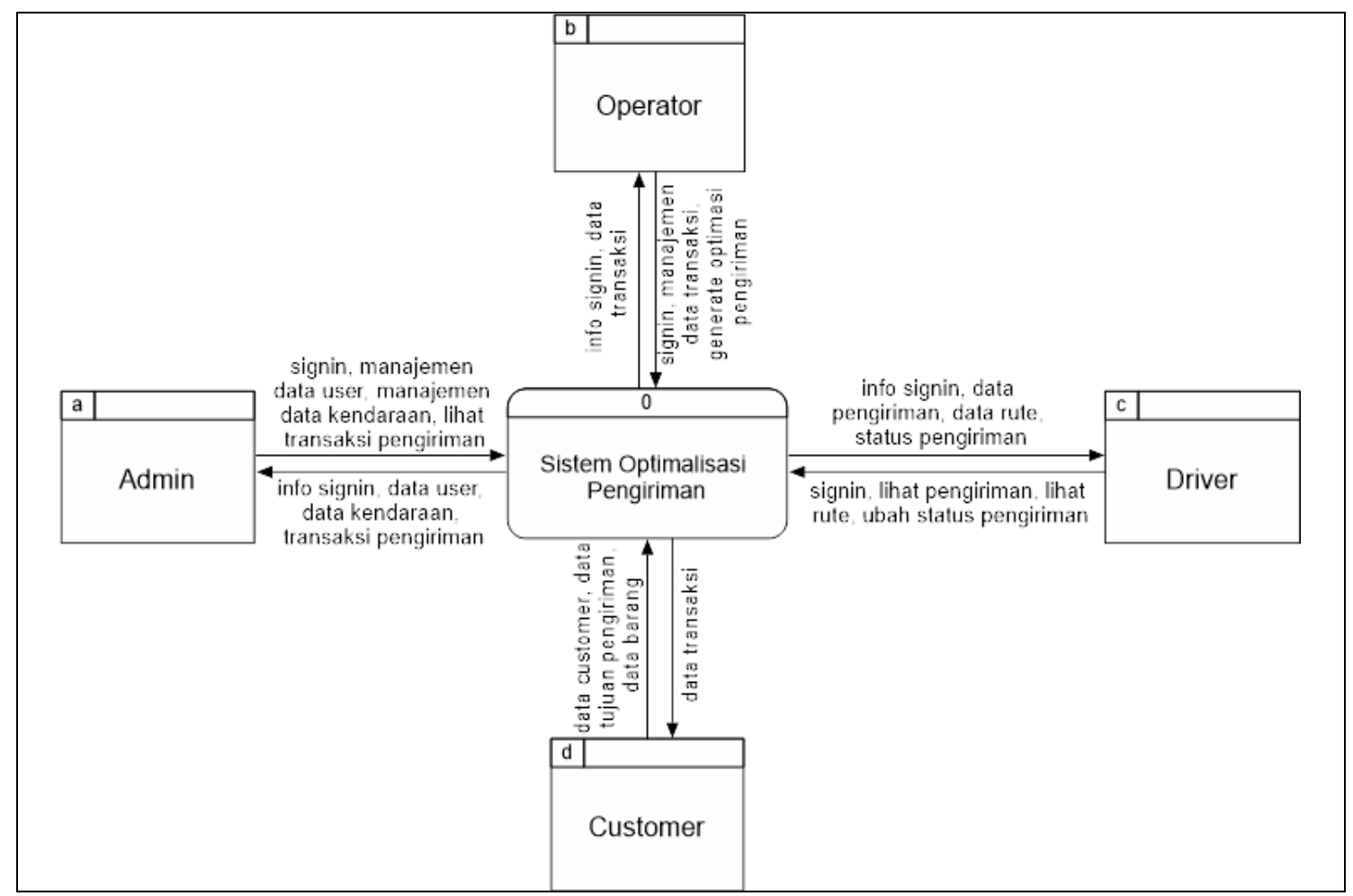

Gambar 3. Diagram Konteks

Gambar 3 menampilkan diagram konteks pada aplikasi optimalisasi pengiriman barang. Entitas yang terlibat dalam aplikasi optimalisasi pengiriman barang adalah customer, operator, admin dan driver. Entitas admin adalah pengguna sistem yang dapat melakukan sign in, manajemen data user dan lihat data transaksi. Entitas customer adalah entitas luar yang memberikan data pengiriman yang akan di-input oleh operator. Entitas operator adalah pengguna sistem yang dapat melakukan manajemen data transkasi dan generate untuk mendapatkan rute pengiriman barang. Entitas driver adalah pengguna sistem yang dapat melihat data pengiriman dan mengubah status pengiriman barang.

\section{b. Struktur Database}

Data yang diperlukan pada aplikasi optimasi pengiriman barang akan disimpan pada struktur database yang dapat dilihat pada Gambar 4. 


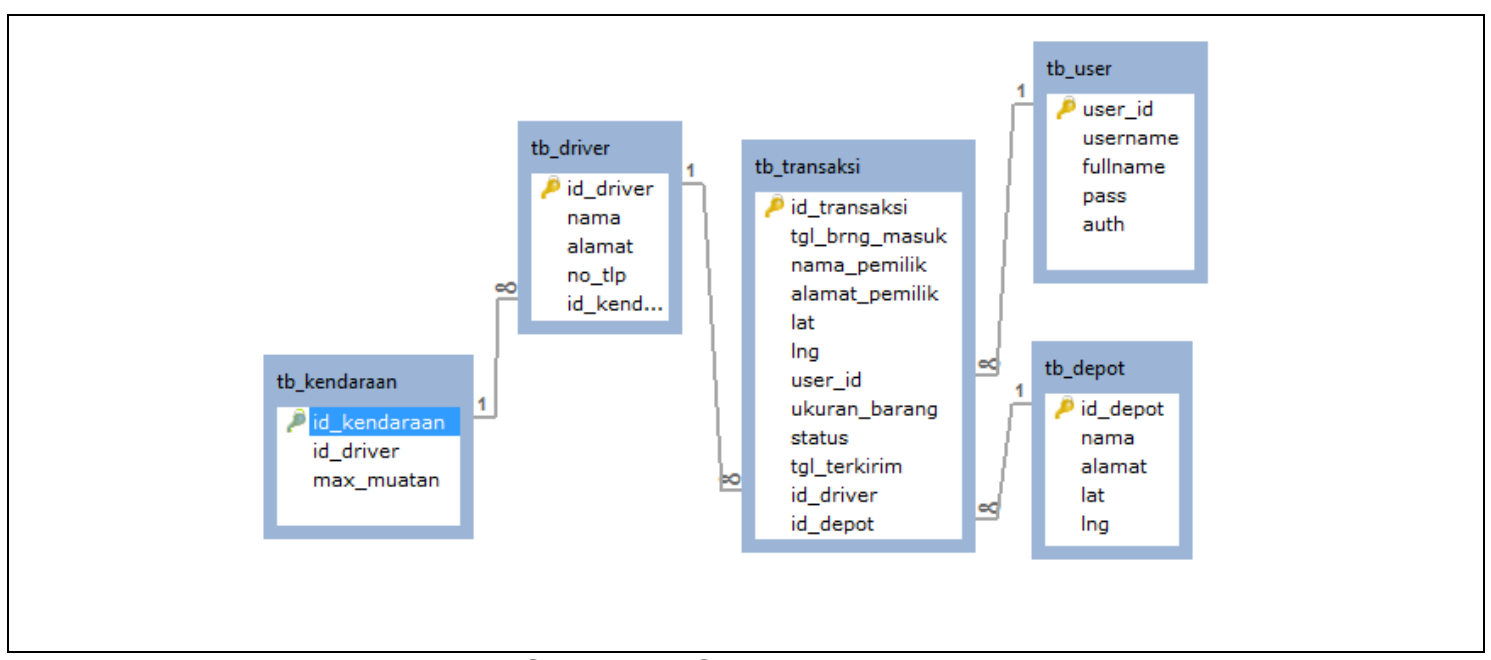

\section{Gambar 4. Struktur Database}

Gambar 4 menampilkan struktur database yang digunakan pada aplikasi optimalisasi pengiriman barang. Tabel utama yang terdapat pada database tersebut antara lain, tabel transaksi yang berisi data setiap transaksi yang masuk untuk dilakukan pengiriman, tabel user digunakan untuk menyimpan data operator, driver dan admin untuk melakukan login pada sistem, tabel driver digunakan untuk menyimpan data driver, tabel kendaraan untuk menyimpan data kendaraan yang dimiliki beserta batas muatannya dan tabel depot untuk menyimpan data alamat perusahaan yang dijadikan titik awal pengiriman.

\subsection{Implementasi Sistem}

Hasil implementasi aplikasi optimalisasi pengiriman barang menggunakan metode tabu search berbasis web sebagai berikut.

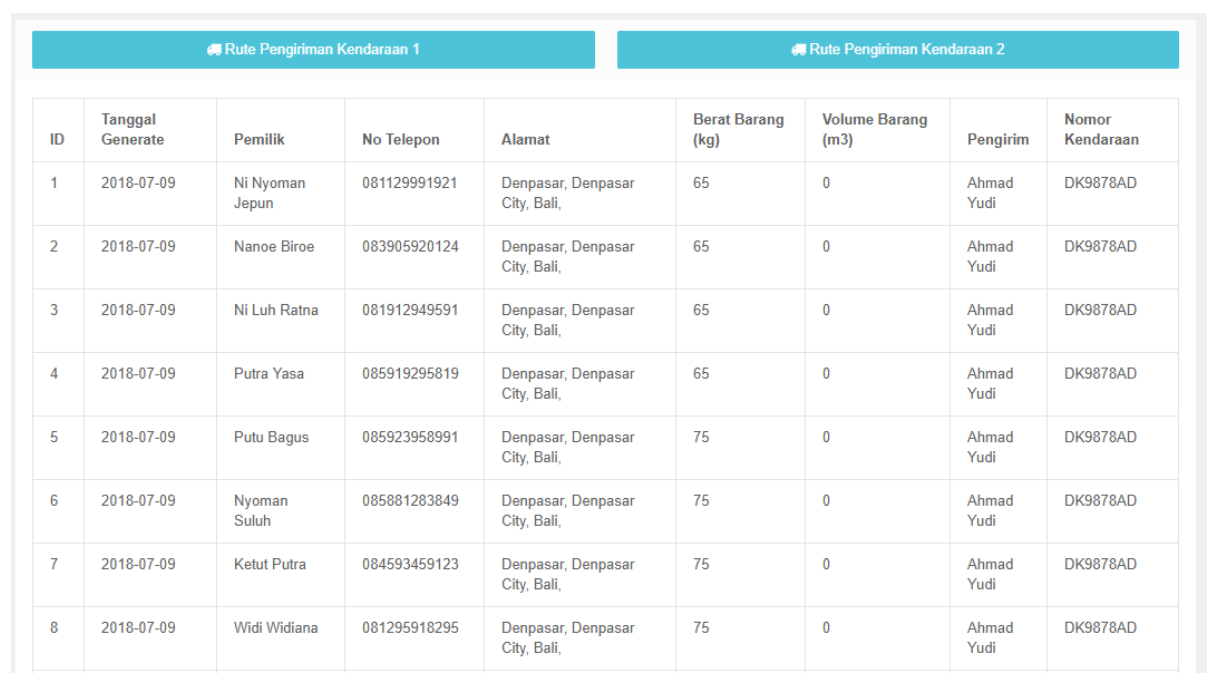




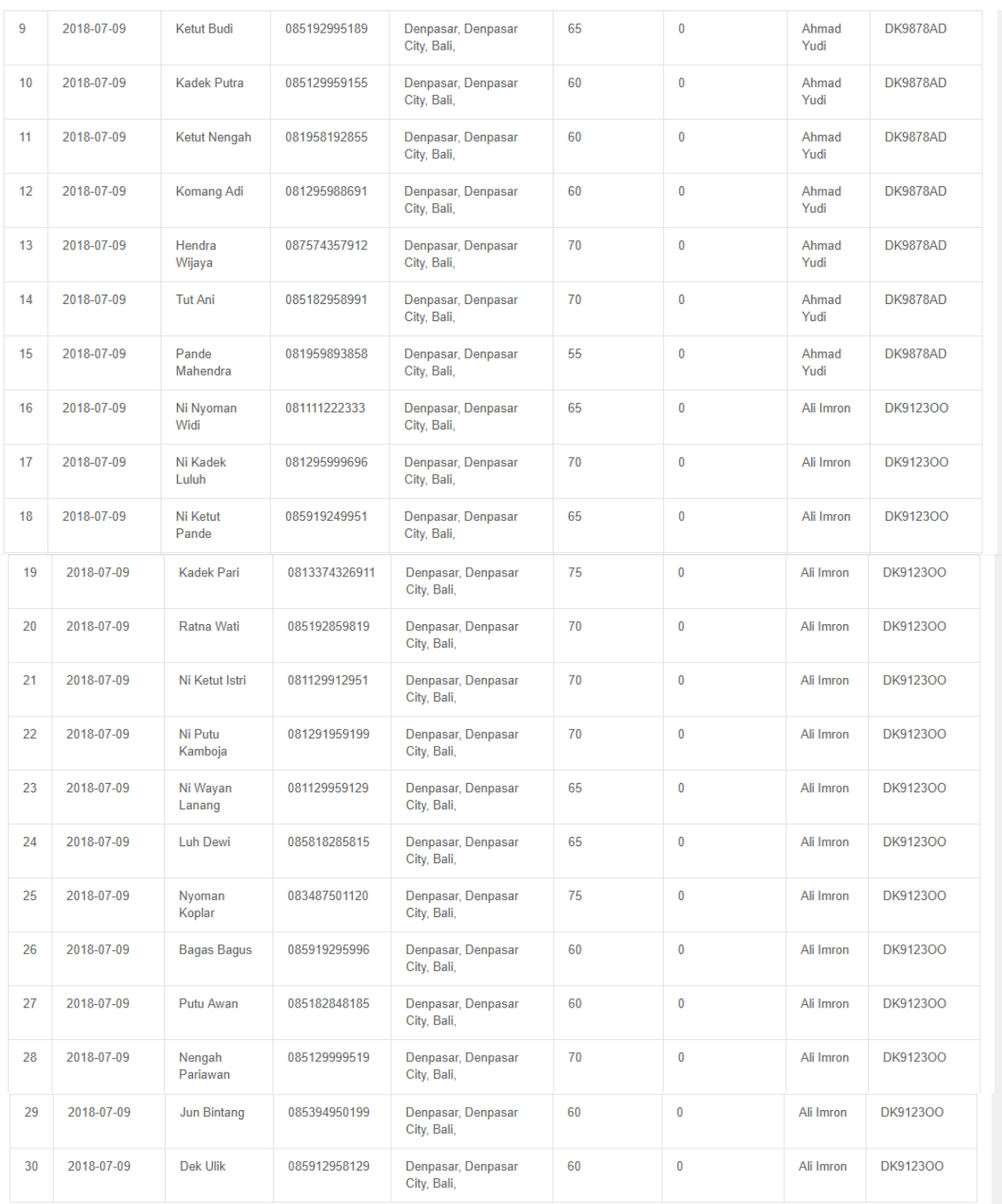

Gambar 5. Data Pengiriman Barang

Data pengiriman barang dijadikan sebagai data acuan untuk mencari rute pengiriman barang dapat dilihat pada Gambar 5. Proses generate rute dibagi menjadi dua buah proses yaitu clustering atau pengelompokkan berdasarkan muatan dan proses pencarian rute untuk masingmasing kendaraan. Hasil uji coba proses clustering dapat dilihat pada Gambar 6. 


\begin{tabular}{|c|c|c|c|c|}
\hline \multicolumn{5}{|l|}{ Kendaraan 1} \\
\hline No Kendaraan & ID Pengiriman & Longitude & Latitude & Muatan \\
\hline 1 & 16 & -8.660954702978932 & 115.20301596289062 & 70 \\
\hline 1 & 27 & -8.65043291549904 & 115.18825308447276 & 70 \\
\hline 1 & 23 & -8.666045784831057 & 115.20380560103365 & 60 \\
\hline 1 & 20 & -8.670118600672335 & 115.2007156962485 & 60 \\
\hline 1 & 17 & -8.67351258015114 & 115.19247595015474 & 60 \\
\hline 1 & 14 & -8.676906528960949 & 115.19899908247896 & 75 \\
\hline 1 & 19 & -8.675888347538939 & 115.2014023417563 & 65 \\
\hline 1 & 4 & -8.672576 & 115.209593 & 65 \\
\hline 1 & 18 & -8.677924707621706 & 115.20438925390624 & 65 \\
\hline 1 & 12 & -8.675888347538939 & 115.2068955058188 & 65 \\
\hline 1 & 30 & -8.685391266732283 & 115.19786612158202 & 75 \\
\hline 1 & 26 & -8.686070037464786 & 115.19796911421724 & 75 \\
\hline 1 & 9 & -8.680300447090136 & 115.20449224654146 & 75 \\
\hline 1 & 6 & -8.676796 & 115.212711 & 65 \\
\hline 1 & 28 & -8.658578841196888 & 115.23357168798827 & 55 \\
\hline \multicolumn{5}{|l|}{ Kendaraan 2} \\
\hline No Kendaraan & ID Pengiriman & Longitude & Latitude & Muatan \\
\hline 2 & 24 & -8.684033721582225 & 115.22783819380709 & 60 \\
\hline 2 & 1 & -8.673808 & 115.217078 & 70 \\
\hline 2 & 25 & -8.687427575244227 & 115.2395111674399 & 70 \\
\hline 2 & 13 & -8.676567135460404 & 115.2226883524985 & 75 \\
\hline 2 & 15 & -8.676567135460404 & 115.2230316752524 & 60 \\
\hline 2 & 22 & -8.675209558390401 & 115.22612158003756 & 65 \\
\hline 2 & 5 & -8.672809 & 115.221202 & 70 \\
\hline 2 & 2 & -8.66753 & 115.22167 & 65 \\
\hline 2 & 11 & -8.662651737921403 & 115.23676458540865 & 60 \\
\hline 2 & 10 & -8.657560610125973 & 115.22234502974459 & 60 \\
\hline 2 & 3 & -8.666681 & 115.215147 & 70 \\
\hline 2 & 8 & -8.66566395673064 & 115.21392503868117 & 65 \\
\hline 2 & 21 & -8.658239431146074 & 115.21513525191256 & 70 \\
\hline 2 & 29 & -8.639231979999426 & 115.21743551855468 & 65 \\
\hline 2 & 7 & -8.658239431146074 & 115.21376196089693 & 75 \\
\hline
\end{tabular}

Gambar 6. Hasil Clustering Data Pengiriman Barang

Hasil dari proses clustering adalah barang yang akan dikirim oleh masing-masing kendaraan dapat dilihat pada Gambar 6 . Proses selanjutnya dalah proses pencarian rute masingmasing kendaraan dengan mencari alternatif rute yang mungkin dihasilkan. Alternatif rute yang dihasilkan sistem untuk kendaraan 1 dan kendaraan 2 dapat dilihat pada Gambar 7. 


\section{Tabulist Pada Masing-Masing Kendaraan}

\begin{tabular}{|c|c|c|}
\hline Iterasi & Jalur & Jarak \\
\hline 1 & $0,4,12,18,19,14,30,26,9,6,20,23,17,27,16,28,0$ & 27576 \\
\hline 2 & $0,4,12,6,19,14,30,26,9,18,20,23,17,27,16,28,0$ & 27411 \\
\hline 3 & $0,6,12,4,19,14,30,26,9,18,20,23,17,27,16,28,0$ & 27125 \\
\hline 4 & $0,4,12,6,19,14,30,26,9,18,20,23,17,27,16,28,0$ & 27411 \\
\hline \multicolumn{3}{|c|}{ Kendaraan 2} \\
\hline Iterasi & Jalur & Jarak \\
\hline 1 & $0,8,3,21,7,10,22,5,2,1,13,15,24,25,11,29,0$ & 29559 \\
\hline 2 & $0,8,3,29,7,10,22,5,2,1,13,15,24,25,11,21,0$ & 29578 \\
\hline 3 & $0,8,3,29,7,21,22,5,2,1,13,15,24,25,11,10,0$ & 28275 \\
\hline 4 & $0,8,3,29,7,21,1,5,2,22,13,15,24,25,11,10,0$ & 27990 \\
\hline 5 & $0,8,3,29,21,7,1,5,2,22,13,15,24,25,11,10,0$ & 28006 \\
\hline 6 & $0,8,3,29,7,21,1,5,2,22,13,15,24,25,11,10,0$ & 27990 \\
\hline
\end{tabular}

Gambar 7. Tabu List Masing-Masing Kendaraan

Alternatif rute terbaik yang dihasilkan masing-masing kendaraan pada setiap proses iterasi dimasukkan dalam tabu list, kemudian dilakukan seleksi rute yang paling optimal dari alternatif tersebut. Rute terpendek yang ada pada tabu list dipilih menjadi rute pengiriman untuk masing-masing kendaraan. Rute pengiriman barang yang terpilih dari hasil seleksi tabu list dapat dilihat pada Gambar 8.

Jalur Terpendek Kendaraan

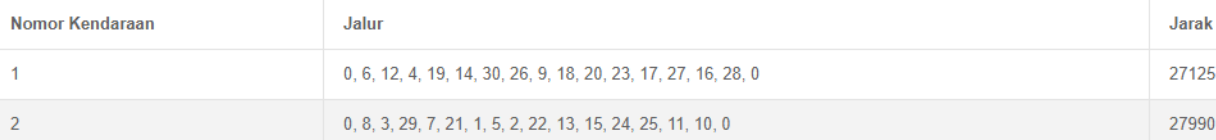

Gambar 8. Hasil Pencarian Rute Pengiriman Barang Masing-Masing Kendaraan

Hasil akhir dari pencarian rute pengiriman barang adalah rute pengiriman barang dan total jarak pengiriman ditampilkan pada Gambar 8. Visualisasi rute pengiriman barang pada Google Maps dapat dilihat pada Gambar 9.

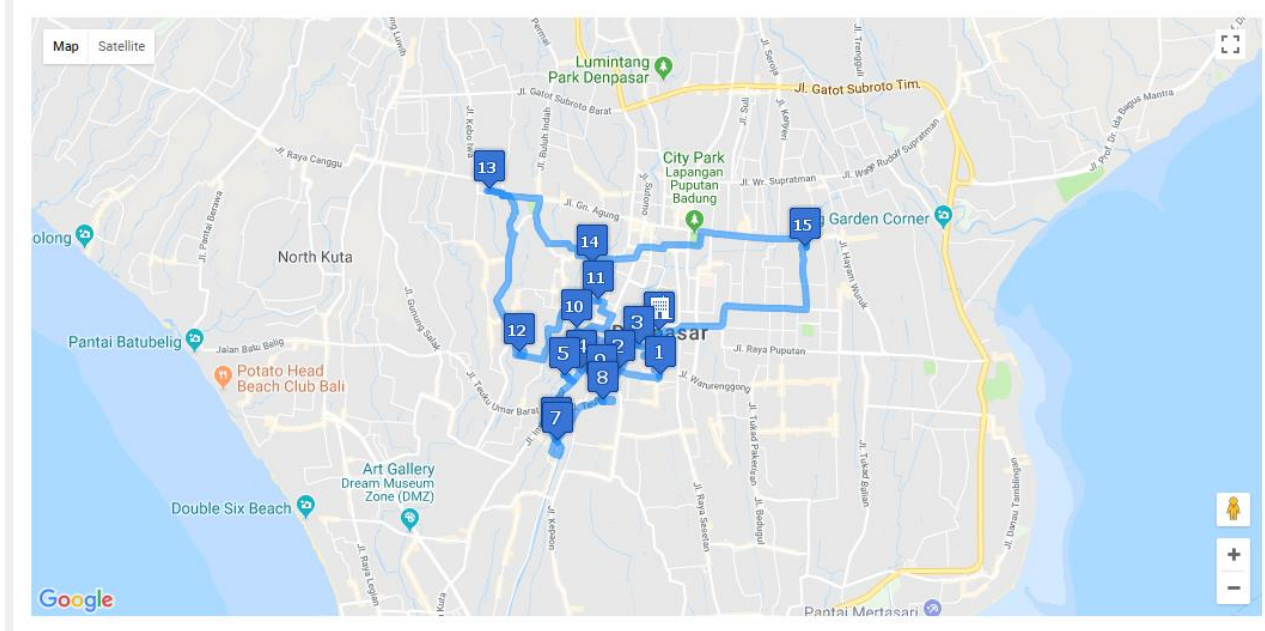

Gambar 9(a). Visualisasi Pencarian Rute Pengiriman Barang Kendaraan 1 


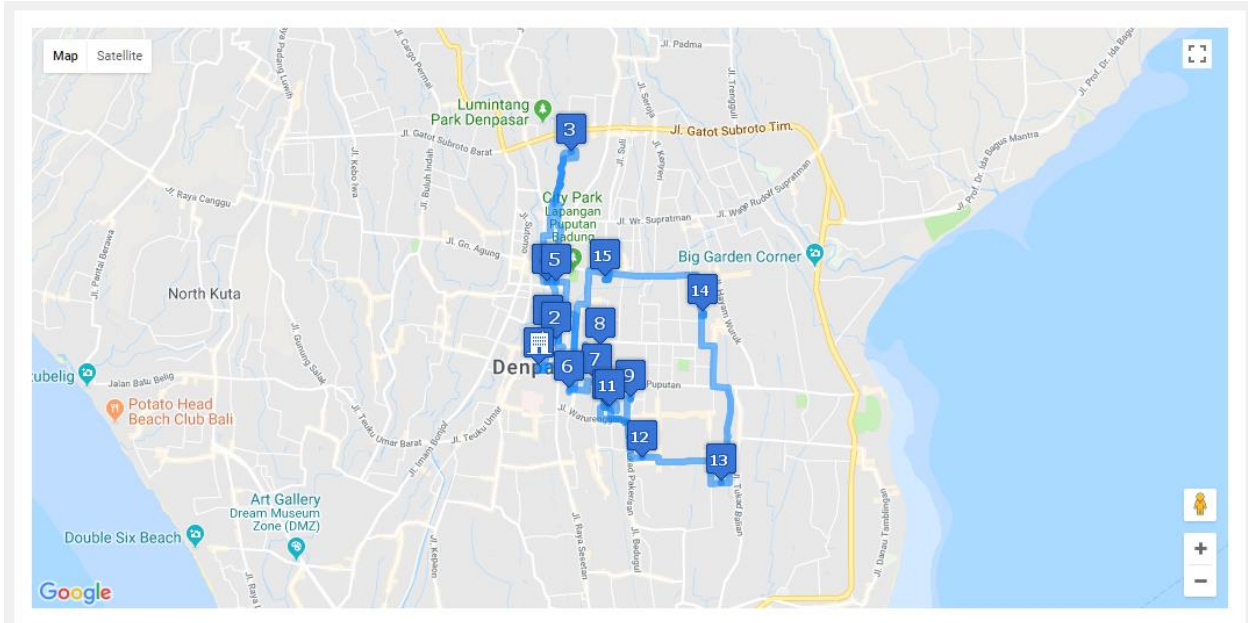

Gambar 9(b). Visualisasi Pencarian Rute Pengiriman Barang Kendaraan 2

Visualisasi rute pengiriman barang untuk masing-masing kendaraan pada google maps ditampilkan pada Gambar 9 . Rute pengiriman barang terdiri dari lima belas titik pengiriman yang dimuai dari depot dan berakhir di depot. Rute ini bisa dilihat oleh masing-masing driver kendaraan tersebut. Rute pengiriman barang untuk masing-masing driver dapat dilihat pada Gambar 10.

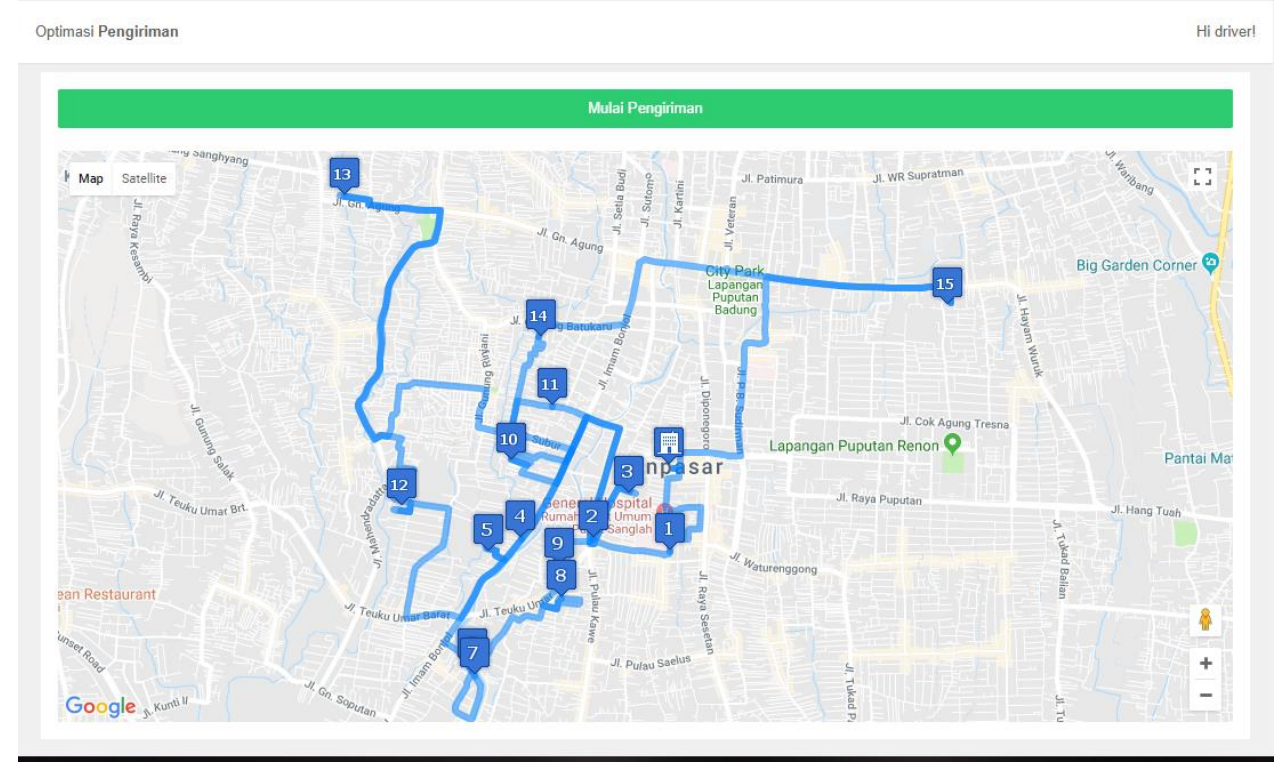

Gambar 10. Rute Pengiriman Barang

Rute pengiriman barang yang harus dilewati oleh driver kendaraan 1 dapat dilihat pada Gambar 10, apabila driver ingin melakukan pengiriman barang klik button pengiriman barang maka akan ditampilkan rute pengiriman dari titik pengiriman 1 menuju titik pengiriman 2.

\section{Kesimpulan}

Aplikasi Optimalisasi Pengiriman Barang menggunakan Metode Tabu Search Berbasis Web yang mampu menyelesaikan model permasalahan CVRP yaitu permasalahan rute pengiriman barang dan kapasitas muatan barang. Aplikasi optimalisasi pengiriman barang membantu mencari rute pengiriman barang yang optimal dan memaksimalkan kapasitas muatan barang sehingga berdampak pada biaya dan waktu pengiriman barang yang lebih rendah. Aplikasi optimalisasi pengiriman barang memanfaatkan Google Maps yang digunakan untuk mencari rute optimal agar driver dapat mengetahui jalur pengiriman barang yang harus dilewati sesuai urutan. 


\section{Daftar Pustaka}

[1] Z. Borcinova, "Two Model of the Capacitated Vehicle Routing Problem," Croatian Operational Research Review, vol. 8, pp. 463-469, 2017.

[2] M. Sari, A. Dhoruri and Eminugroho, "Penyelesaian Capacitated Vehicle Routing Problem menggunakan Saving Matriks, Sequential Insertion dan Nearest Neighbour di Victoria RO," Jurnal Matematika, vol. 5 No. 3, pp. 1-5, 2016.

[3] S. E. Fradina and F. Y Saptaningtyas, "Penerapan Algoritma Sweep dan Algoritma Genetika pada Penyelesaian Capacitated Vehicle Routing Problem (CVRP) untuk Optimasi Pendistribusian Gula," Jurnal Matematika, vol. 6 No. 2, pp. 63-65, 2017.

[4] Sulistiono and N. S. M. Mussafi, "Rancang Bangun Vehicle Routing Problem menggunakan Algoritma Tabu Search," Jurnal FOURIER, vol. 4 No. 2, pp.113-122, 2015.

[5] S. Faiz, S. Krichen and W. Inoubli, "A DSS based on GIS and Tabu search for Sloving the CVRP: The Tunisian Case," The Egyptian Journal of Remote Sensing and Space Sciences, pp. 105-110, 2014.

[6] P. W. Buana, "Penemuan Rute Terpendek Pada Aplikasi Berbasis Peta," Lontar Komputer, vol. 1 No. 1, p. 2, 2010.

[7] S. Rupiah, Mulyono and E. Sugiharti, "Efektivitas Algoritma Clarke-Wright dan Sequential Insertion dalam Penentuan Rute Pendistribusian Tabung Gas LPG," UNNES Journal of Mathematics, vo. 6 No. 2, pp. 199-200, 2017.

[8] T. Caric and H. Gold, Vehicle Routing Problem, Austria: In-Teh, 2008.

[9] I. N. Piarsa, I. G. Udayana Putra and A. A. K Oka Sudana, "The Implementation of Tree Method in Geographic Information System of Mother Temple Mapping and its Linkage based on Web," International Journal of Computer Applications, vol. 148 No. 10, pp. 910, 2016.

[10] E. Prahasta, Sistem Informasi Geografis Konsep-Konsep Dasar (Perspektif Geodesi \& Geomatika), Bandung: Informatika, 2009.

[11] S. Rahayu, I. N. Piarsa and P. W. Buana, "Sistem Informasi Geografis Pemetaan Daerah Aliran Sungai Berbasis Web," Lontar Komputer, vol. 7 No. 2, pp. 75-76, 2016.

[12] G. Svennerberg, Beginning Google Maps API 3, America: Appres, 2010.

[13] A. Rahmi, I. N. Piarsa and P. W. Buana, "FinDoctor - Interactive Android Clinic Geographical Information System Using Firebase and Google Maps API," International Journal of New Technology and Research, vol. 3 No. 7, pp. 8-10, 2017.

[14] P. M. Hasugian, "Pengembangan Aplikasi Untuk Memepermudah Pencarian Rumah Sakit Umum Dengan Algoritma Tabu Search," Journal of Informatic Pelita Nusantara, vol. 2 No. 1, pp. 2-3, 2017. 